\title{
Parts Of The Whole: The Virtue of Books
}

\author{
Dorothy Wallace \\ Dartmouth College, dorothy.wallace@dartmouth.edu
}

Follow this and additional works at: https://digitalcommons.usf.edu/numeracy

Part of the Elementary and Middle and Secondary Education Administration Commons, and the Science and Mathematics Education Commons

\section{Recommended Citation}

Wallace, Dorothy. "Parts Of The Whole: The Virtue of Books." Numeracy 5, Iss. 2 (2012): Article 8. DOI: http://dx.doi.org/10.5038/1936-4660.5.2.8 


\title{
Parts Of The Whole: The Virtue of Books
}

\begin{abstract}
This column argues that the majority of commercial textbooks do not serve students well. Strategies for change include clearly distinguishing the textbook requirements of different priority subjects and assembling writers who can address, in addition to content development, the cognitive level of the children as well as writing in an age-appropriate way. A discussion of the forces that produce current texts leads to the recommendation that textbooks be a focus of research and improvement rather than the byproduct of an individual's lecture notes.
\end{abstract}

\section{Keywords}

quantitative literacy, numeracy, education management

Creative Commons License

(c) (1) (9)

This work is licensed under a Creative Commons Attribution-Noncommercial 4.0 License

\section{Cover Page Footnote}

Dorothy Wallace is a professor of mathematics at Dartmouth. She was 2000 New Hampshire CASE Professor of the Year, and the lead PI of the seminal NSF project, Mathematics Across the Curriculum. She recently finished a text in mathematical biology for first-year students, "Situated Complexity." She was a charter board member of the National Numeracy Network and is now co-editor of this journal.

This column is available in Numeracy: https://digitalcommons.usf.edu/numeracy/vol5/iss2/art8 


\section{Parts Of The Whole A Column by $\mathrm{D}$. Wallace}

The problem of how best to improve the numeracy of a society is a thorny one, embracing the learning process of a single student but rising in scale to include the management and alteration of an entire system of education. With the issue of quantitative literacy always in mind, this column will consider various aspects of the systemic workings of education, the forces acting on classrooms, teachers and students, and mechanisms of both stasis and change.

\section{The Virtue of Books}

It is extremely tempting to offer the following definition:

A textbook is an expensive and lengthy exposition of one or more important topics, intentionally written so poorly that no sane individual would read it unless coerced.

Dryness of exposition, absence of any narrative structure, and a disjointed visual presentation designed to conceal these flaws, characterize nearly all textbooks. Barren of literary vision, these volumes represent an uneasy collection of political compromises with little regard to either cognitive or classroom management issues. They are not so much written, as compiled. College teachers routinely receive preliminary copies of new texts to review before publication. Reading these is pure punishment. To twist the poetry of a master, what dark Satanic Mill forces such prose upon mere innocent children? We should all stand amazed at one of the more befuddling outcomes of our educational system.

Most textbooks are the result of a particular process. The professor, having taught his or her course from a variety of materials and sources, develops lecture notes that represent what ought to be covered in lectures. Eventually these notes are complete enough to share with students. At this point a textbook is proposed to a publisher, based on the notes. The publisher hopes that the text will sell because it is the first in a growing field, or because it has more in it than its competitors, or because of the prestige of the author or the author's institution. When a draft of the text is completed it is sent to other professors for review, with the hope of finding out whether these professor would choose to teach from it. If the book is intended for use at the K-12 levels, the publisher will want to know if it meets state standards and otherwise satisfy committees of people who will neither learn nor teach from the book.

Maybe it is worth pointing out how different this is from the way ordinary books are published. To decide if a novel or popular science book is worth publishing, the author and publisher both want to know how well the readers of 
the book will like it, and they test the draft manuscript on people who are similar to the readers they hope to impress. Rarely is a textbook tested to see how readable it is by students, or whether they like it. If anything, it is assumed that no student would read the text voluntarily, and that probably they won't enjoy reading it when they are required to do so.

Publishing, even the publishing of textbooks, is a free market enterprise. Presumably the laws of supply and demand ought to be at work here, so that superior books would dominate the market. The system, which ought to work reasonably well, has gone seriously awry for the simple reason that those who choose textbooks have no intention of reading them. Texts are chosen because they cover certain material, have exercises in them so teachers are spared some work, and satisfy the assorted demands of a constituency completely separate from the readership of the book. Here is a purely systemic issue that is easily solved. Merely insist that, before adopting a text, a mixed group of parents, administrators, teachers and students spend the time necessary to read the whole of it aloud to each other. Few textbooks would survive this test. Perhaps the adult readers would admit that, in the words of Emerson, "The virtue of books is to be readable."

This matter is a critical one from the standpoint of managing education. In our hierarchy of priorities, many important kinds of knowledge are relegated to second or third priority, precisely because it is possible for children to learn those things in a relatively independent fashion. If children did so, it would make managing the whole educational enterprise much easier. Textbooks completely thwart this approach. A series of disconnected subjects leads to disconnected knowledge. Knowledge presented in unmemorable prose is very hard to remember. Writing aimed at the teacher rather than the student is sure to confuse the latter, causing the student to feel much stupider than necessary, and possibly abandoning further attempts to learn.

As a public school child in the third grade in California, I benefited from an entire year of California history, of which I remember little. The retained aspects could have been replaced completely by "Dragon Parade," a great story about Chinese immigrants to San Francisco, one over-the-top sensational story about the Donner party, a viewing of "Paint Your Wagon," and an informative visit to a California mission. These missions have been conveniently spaced up and down the length of California, presumably for pedagogical purposes. (No! They are actually one day's horse ride between. I do remember some things.)

For second- and third-priority subjects, a good first step in making our educational system manageable would be to throw out every single textbook. These tedious volumes ought to be replaced by real books written by children's writers for children to read. The writing of child-friendly texts on second-priority subjects is an important enough activity to justify public resources, if we expect 
children to learn anything independently. An even more cost-effective use of resources would be to collect existing excellent children's literature and provide a framework for using it coherently in the classroom. Assembling and organizing collections of child-friendly materials around a theme can be done on a statewide or systemic basis and does not have to be taken out of the teacher's hide. School librarians should be enlisted in such activity.

First-priority material is a different matter altogether. The teacher deserves an outline of the plan of action of a text, based on both cognitive and management principles. The teacher deserves ready-made evaluation tools and a plan for implementing them. First-priority material, by definition, requires a lot of teacher attention, so current textbooks are often written more with the teacher in mind. It would be far less profitable for publishers, but far less expensive for schools, if the teacher were provided with an extensive text that included many notes on cognition and pedagogy. The students should be given only things that it is reasonable to expect them to be able to read at their level. These materials need to be clear, engaging, written for children instead of adults, and based on the cognitive structures presumed to be in place for those students at that time.

Solving the problem of texts for first-priority subjects is also a systemic issue. If publishers followed the recommendations of the last paragraph, they would lose money. Publishers work inside a system too. Furthermore, a good text for conceptually difficult material, organized according to the recommendations of this essay, has yet to be written. It is unlikely to be written by a single independent author. The only solution visible at this point is for a whole educational system, such as a state, to undertake the construction of its own texts. It is unusual for a state to be engaged in such activities, but the state of Montana created some of its math curriculum, relying on state resources and outside funding. The National Science Foundation, for example, would do well to sponsor the construction of mathematics texts by a group of individuals that includes experts in children's writing, cognition, math education, mathematics, statistical design, and evaluation. Such a group would have to begin by delineating the cognitive structure of every topic to be covered and end by providing pedagogy addressing all aspects of that structure. A substantially improved mathematics text would be no small project.

It would be interesting to identify examples of writing coming out of the textbook industry that are readable by actual students. I personally know of two such math texts (not counting my own!), one of which I would describe as an interesting read as well. I will tell you about the two texts, and the stories of how I came to these conclusions.

My daughter suffered from an awkward transition out of her little K-6 school and into the local K-8 school for her $7^{\text {th }}$ grade. It was not easy for her to counter what appeared to be a strong expectation on the part of her teachers that she 
would perform poorly, no matter what. In December she announced she was not going back, and would accept my offer of home schooling for the remaining years before entering high school. She did the next year and a half of her schooling in my office at work. The first year our approach to math was seriously ad hoc, and I knew I needed some support from a textbook to start algebra the next year. I borrowed a copy of the local school's algebra text, part of the University of Chicago School Mathematics Project. This turned out to be a great book. My daughter learned a lot of algebra directly, by herself, through reading this text. When she tried the homework problems and got stuck I had to sort her out a little, but basically she taught herself the entirety of the material. If she had been in a regular school situation she might not have read the text, but rather depended on listening to explanations from the instructor. But, because of the circumstances, I can truthfully say that this text is quite readable and understandable by at least one student who does not consider herself to be particularly strong in math.

My appreciation of the second text comes from the one instance in which I was asked to teach introductory statistics at Dartmouth. Many years ago our department had the strange unofficial policy of giving our intro stats course to the people in the department who knew absolutely the least about statistics, myself as example. The assumption (partially true) was that any professional mathematician should be able to teach this course. One quarter in advance the instructor was given an entire box of statistics books and told to choose one for the course. Most people picked the one used the last time. Like a fool, I tried to read them all. If you try to read a dozen texts in a subject you don't know, you will see it is pretty easy to pick out the ones that are readable, because you are trying to learn the subject from the book itself. I found exactly one text that could teach me the actual concepts of statistics in a readable and very enjoyable way: Freedman, Pisani and Purves (Statistics). By the time I read it I was ready to be impressed by a linear development of a concept, supported with examples, and uninterrupted by colorful and distracting text boxes full of formulas or worse, code. It was refreshing to be in the company of these relaxed experts as they told their stories.

Regulating scope, sequence, approach, and often pedagogy, a textbook affects the whole educational system as much as it may itself be affected by it. To adjust the system, we must rework the books that guide it. Textbooks must be written that allow for appropriate construction of cognition and control of variation in the classroom. Any material children will read independently must offer a comprehensible, entertaining experience. The readability of a text, its interest to students, and its vibrancy must be tested directly on students, not on school boards, principals and panels of adult experts.

Already we see quite a few examples of quantitative reasoning textbooks on the market. The beauty of our subject is that every piece of mathematics in such a textbook has many interesting stories behind it. Textbook authors need to tell 
these stories, and the quantitative analysis that goes with them, with the grace and enthusiasm that will motivate students to read the text willingly, and enjoy doing so. To steal a second time from Blake, please do bring us our arrows of desire. It is the least our students deserve. 